\title{
Secondary organic aerosol from ozone-initiated reactions with terpene-rich household products
}

\author{
Beverly K. Coleman ${ }^{a,{ }^{*}}$, Melissa M. Lunden ${ }^{\mathrm{b}}$, Hugo Destaillats ${ }^{\text {b,c }}$, William W Nazaroff ${ }^{\mathrm{a}}$ \\ ${ }^{a}$ Department of Civil and Environmental Engineering, University of California, Berkeley, CA \\ 94720, USA; ${ }^{b}$ Indoor Environment Department, Environmental Energy Technologies Division, \\ Lawrence Berkeley National Laboratory, Berkeley, CA 94720, USA; ${ }^{\mathrm{C}}$ Department of Civil and \\ Environmental Engineering, Arizona State University, Tempe, AZ 85287, USA
}

\section{Abstract}

We analyzed secondary organic aerosol (SOA) data from a series of small-chamber experiments in which terpene-rich vapors from household products were combined with ozone under conditions analogous to product use indoors. Reagents were introduced into a continuously ventilated $198 \mathrm{~L}$ chamber at steady rates. Consistently, at the time of ozone introduction, nucleation occurred exhibiting behavior similar to atmospheric events. The initial nucleation burst and growth was followed by a period in which approximately stable particle levels were established reflecting a balance between new particle formation, condensational growth, and removal by ventilation. Airborne particles were measured with a scanning mobility particle sizer (SMPS, 10 to $400 \mathrm{~nm}$ ) in every experiment and with an optical particle counter (OPC, 0.1 to 2.0 $\mu \mathrm{m})$ in a subset. Parameters for a three-mode lognormal fit to the size distribution at steady state were determined for each experiment. Increasing the supply ozone level increased the steadystate mass concentration and yield of SOA from each product tested. Decreasing the airexchange rate increased the yield. The steady-state fine-particle mass concentration $\left(\mathrm{PM}_{1.1}\right)$ ranged from 10 to $>300 \mu \mathrm{g} \mathrm{m}^{-3}$ and yields ranged from $5 \%$ to $37 \%$. Steady-state nucleation rates and SOA mass formation rates were on the order of $10 \mathrm{~cm}^{-3} \mathrm{~s}^{-1}$ and $10 \mu \mathrm{g} \mathrm{m}^{-3} \mathrm{~min}^{-1}$, respectively.

\footnotetext{
* Corresponding author information: Department of Civil and Environmental Engineering, University of California, Berkeley, 605 Davis Hall, Berkeley, CA 94720. E-mail: BKColeman@lbl.gov. TEL: +1(510) 486-6072. FAX:

$+1(510)$ 486-7303.
} 
Keywords: secondary organic aerosol, cleaning products, indoor air quality, terpenes, limonene, ozone, size distribution, nucleation, condensation

\section{Introduction}

Terpenes and ozone are commonly present indoors, and their reactions can produce particles (Weschler and Shields, 1999; Long et al., 2000; Wainman et al., 2000; Sarwar et al., 2004; Liu et al., 2004). Consumer products, such as cleaning agents and air fresheners, are common sources of terpenes (Nazaroff and Weschler, 2004). Ozone is routinely present indoors because of ventilation with ozone-containing outdoor air (Weschler, 2000).

Particle inhalation raises health concerns (Pope and Dockery, 2006). Deposition in the lungs is size-dependent (Yeh et al., 1996; Asgharian and Price, 2007), and the health effects associated with aerosol exposure depend on particle size and concentration (Oberdörster, 2001; Peters et al., 1997). The exposure impacts of indoor pollutants are amplified because (a) people spend a high proportion of their time indoors, (b) emissions that occur indoors are diluted into confined volumes and removed at slow ventilation rates, and (c) people tend to be in close proximity to indoor pollutant sources (Nazaroff, 2008). Consequently, it is important to characterize both the source strength and size distribution of significant indoor particle sources.

Secondary organic aerosol (SOA) formation from ozone-terpene interactions has been widely studied in relation to atmospheric organic aerosol formation. Those studies have uncertain direct applicability for elucidating SOA formation indoors. Several studies have measured SOA formation and growth from ozone reactions with pure terpenes or with terpenecontaining products under indoor-relevant conditions. Most of these studies measured particles using an optical particle counter (Weschler and Shields, 1999; Wainman et al., 2000; Weschler and Shields, 2003; Sarwar et al., 2003; Sarwar et al., 2004; Hubbard et al., 2005; Singer et al., 
2006a). Optical particle counters (OPC) typically measure only particles that are $100 \mathrm{~nm}$ or larger and thus cannot characterize the ultrafine particles that are an essential component of particle nucleation and growth. A few studies have characterized ultrafine particles using a scanning mobility particle sizer (SMPS) to investigate nucleation and growth in these cases: (a) use of a pine-oil based cleaner in the presence of ozone (Long et al., 2000); (b) peeling of oranges in the presence of ozone (Vartainen et al., 2006); and (c) adding limonene to an office environment in which an ionizing air purifier was used (Alshawa et al, 2007).

In the present study, particle formation and size-distribution dynamics are investigated with an SMPS and an OPC for experiments in a small, flow-through chamber. Ozone reacted with vapor emissions of terpene-containing consumer products (two cleaning products and an air freshener) at indoor-relevant conditions. A previous paper reported the consumption of primary constituents and the formation of secondary products from these experiments, emphasizing gaseous species (Destaillats et al., 2006). Here, particle data from the same experiments are presented in detail and analyzed to characterize particle size distributions. The effects on SOA production of factors such as air-exchange rate and ozone level are investigated. Particle formation and growth dynamics are analyzed, and the particle mass formation rate is modeled.

\section{Experimental conditions}

Experiments were conducted in a Teflon-lined 198-L rectangular chamber. Details of the experimental set-up and gas-phase chemical analyses were presented in Destaillats et al. (2006). Briefly, cleaning product vapor was continuously introduced into the chamber and, after a steady-state condition was reached, continuous ozone addition commenced. The product vapor was introduced through Teflon tubing in one bottom corner of the chamber while ozone was introduced through Teflon tubing in the diagonal opposite bottom corner. Particle sampling was 
done at the middle of the chamber ceiling. Experiments were performed at $23.0 \pm 0.5{ }^{\circ} \mathrm{C}$.

Three cleaning products were tested: a pine oil cleaner (POC); an orange-oil degreaser (OOD); and a heated, scented-oil air freshener (AFR). The reactive constituents likely to contribute to SOA formation are listed here; detailed composition of the products is reported in Singer et al. (2006b). The OOD contained only one terpene, d-limonene. The POC contained several volatile and reactive constituents, including d-limonene, terpinolene, $\alpha$-terpinene and $\alpha$ terpineol. The AFR was the most complex mixture, with more than 30 volatile terpenes, terpenoids, and other compounds, the most reactive of which were d-limonene, linalool, dihydromyrcenol, $\beta$-citronellol, and linalyl acetate.

For each product, three experiments were conducted with two ozone supply levels and two air-exchange rates (AERs) in the following configurations: $130 \mathrm{ppb}, 3 \mathrm{~h}^{-1}$ (denoted $\mathrm{HH}$ ); 60 ppb, $3 \mathrm{~h}^{-1}$ (denoted $\mathrm{MH}$ ); and $130 \mathrm{ppb}, 1 \mathrm{~h}^{-1}$ (denoted HL). Seven additional experiments with the POC were executed. Conditions for each experiment are summarized in Table 1. The total cleaning product constituent levels were similar for each of the three configurations and the total amount of reactive terpenes and terpenoids in the inflow were also similar for each cleaning product, approximately $700 \mathrm{ppb}$. All experiments, unless otherwise stated, were performed with zero grade air (Airgas) humidified by means of a sparger to $50 \%$ relative humidity (RH). The zero air was virtually particle free, but flowing the air through the sparger containing pellets of activated carbon $(\sim 0.5 \mathrm{~cm}$ in diameter) introduced "seed" particles. With the sparger in use, the supply air contained a particle concentration of $\sim 400 \mathrm{~cm}^{-3}$. The geometric median diameter was $~$ $30 \mathrm{~nm}$, the geometric standard deviation was 1.3 , and the mass concentration was $\sim 0.005 \mu \mathrm{g} \mathrm{m}{ }^{-3}$. With the pine-oil cleaner, the range of ozone supply levels was extended (POC-VH and POC-LH) and a replicate experiment was conducted (POC-HH1 and POC-HH2). Four 
supplemental experiments were also conducted. In POC-Rev, the cleaning product vapor was introduced into the chamber that already contained a steady-state level of ozone. In POC-NOx, a steady-state level of $74 \mathrm{ppb}$ of $\mathrm{NO}_{2}$ and $1.75 \mathrm{ppb}$ of $\mathrm{NO}$ was present in the chamber, together with the VOC mixture and before addition of ozone, to explore the effect of the nitrate radical on oxidative chemistry. In POC-Seed, laboratory air was used instead of zero air to investigate the effects of a more realistic atmospheric seed particle distribution on secondary product formation. The POC-NOx, POC-Rev, POC-Seed experiments were performed at an AER of $3 \mathrm{~h}^{-1}$ and $\sim 130$ ppb supply ozone. To investigate the effect of water vapor, a POC-Dry experiment was performed using zero-air without any humidification at $3 \mathrm{~h}^{-1}$ and $\sim 60 \mathrm{ppb}$ of ozone in supply air.

Tracer gas tests confirm that the chamber was well mixed (Destaillats et al., 2006). A comparison of estimated characteristic times for mixing and reaction indicates that these two processes have similar time scales. Particles were only sampled from one position in the chamber. Some features of the particle data could be influenced by spatial variability given the burst nature of nucleation.

\section{Particle measurement and analysis}

\subsection{Instruments}

Aerosol measurements were performed using a scanning mobility particle sizer (SMPS) in every experiment and an optical particle counter (OPC) in some experiments. The SMPS measured particles in the diameter range $0.008-0.415 \mu \mathrm{m}$ in $64 \mathrm{bins}$; data from 0.01 to $0.4 \mu \mathrm{m}$ were used for analysis in this paper. The SMPS consists of a differential mobility analyzer (3701A, TSI Inc.) and a condensation particle counter (3760, TSI Inc.). The SMPS performed a complete scan (up and down the size distribution) approximately every two minutes. The data were collected and inverted using the Labview interface with software written by D Collins 
(Texas A\&M University) and P Chuang (UCSC) and analyzed using Igor (Wavemetrics Inc.) with custom routines. The OPC (Lasair 1003, Particle Measuring Systems, Inc.) measured 0.1-2 $\mu \mathrm{m}$ diameter particles in 8 bins.

For both instruments, particle volume concentration was estimated by multiplying the measured number concentration by $\left(\pi / 6 \times \mathrm{GMD}^{3}\right)$, where the geometric mean diameter of a bin, GMD, is the square root of the product of the upper and lower bin diameters. A particle density of $1 \mathrm{~g} \mathrm{~cm}^{-3}$ was assumed in converting volume to mass; this may underestimate particle mass concentration as some studies have reported the density of organic atmospheric particles to be 1.2 to $1.5 \mathrm{~g} \mathrm{~cm}^{-3}$ (Khlystov et al., 2004; Turpin and Lim, 2001).

The OPC sampled for 1 minute every 2 minutes, counting particles in eight bins simultaneously. The lower bin bounds, as calibrated by the manufacturer with polystyrene latex (PSL) particles, were $0.1,0.2,0.3,0.4,0.5,0.7,1.0$, and $2.0 \mu \mathrm{m}$. However, the instrument's response is influenced by the particle's refractive index, $m$, which depends on its chemical composition. The refractive index of PSL is 1.588. Organic particles tend to have a lower refractive index (Dick et al., 2007). Accurately sizing particles with a different refractive index requires scaling the bin bounds. For instance, a $0.15 \mu \mathrm{m}$ particle of oleic acid $(m=1.46)$ would be sized as a $0.1 \mu \mathrm{m}$ particle in an OPC calibrated using PSL (Hand and Kreidenweis, 2002).

\subsection{Alignment routine}

Hand and Kreidenweis (2002) calibrated the same model of OPC as used in this study with PSL $(m=1.588)$, dry ammonium sulfate $(m=1.53)$, and oleic acid $(m=1.46)$. From those data, they developed polynomials for scaling the manufacturer's bin bounds. In the present study, a routine was developed that employed these scaling polynomials in aligning the data collected where the size range measured by the OPC and SMPS overlap. At each time step, the alignment 
routine scanned the range of possible $m$ values from 1.46 to 1.59 , using increments $\Delta m=0.01$, calculated OPC bin bounds, summed the SMPS number concentrations within those bounds, and compared the results to the OPC number concentration. The result was a time-dependent $m$ value that produced optimal alignment between the OPC and SMPS data, determined using the leastsquares difference between the SMPS and adjusted OPC concentrations. Only two or three size bins of the OPC data overlapped with the size range of the SMPS data. The refractive index determined from this routine is not intended to be a robust indication of the refractive index of the particles. Instead, the purpose was to determine an appropriate adjustment of the OPC bin bounds, to improve estimates of particle mass concentrations.

The results matched our expectation that SOA has a refractive index similar to that of oleic acid. The alignment routine indicated $m=1.46-1.49$. The OPC bins were scaled for oleic acid and the lower bin bounds used were $0.15,0.24,0.36,0.47,0.62,0.89$, and $1.1 \mu \mathrm{m}$. (The eighth bin was not modeled.) For these seven bins, total mass concentration is equivalent to $\mathrm{PM}_{1.1}$ because the maximum particle size detected was less than $1.1 \mu \mathrm{m}$.

\subsection{Wall losses}

The pseudo first-order rate coefficient for particle deposition to chamber surfaces, $L_{\text {dep }}$, was determined using equation 1 at each particle scan.

$$
L_{d e p}=\int_{D_{p, \min }}^{D_{p, \max }}\left(\beta_{d e p}\left(D_{p}\right)\right)\left(\frac{d N}{d \log D_{p}}\right) d \log D_{p}
$$

The size-dependent deposition loss-rate coefficients, $\beta_{\text {dep }}$, were estimated using the model of Lai and Nazaroff (2000). This model requires the input of a friction velocity to characterize nearsurface flows. The actual friction velocity in the chamber was unknown, so a range of plausible values was used. The calculated characteristic time for deposition was very long compared to 
removal by ventilation. For example, in experiment $\mathrm{POC}-\mathrm{MH}$, the minimum characteristic time for surface deposition throughout the duration of the experiment (which occurs at the peak number concentration) was 70 to $700 \mathrm{~h}$, respectively, for friction velocities of 3 to $0.3 \mathrm{~cm} \mathrm{~s}^{-1}$. The characteristic time for particle loss by ventilation was $0.3 \mathrm{~h}$. Consequently, we concluded that particle deposition to chamber surfaces could be neglected in further analysis.

Characteristic times for deposition of condensable vapors to walls were also calculated using the Lai and Nazaroff (2000) model, but using a range of diffusion coefficients for semivolatile products of terpene oxidation $\left(0.04\right.$ to $\left.0.08 \mathrm{~cm}^{2} \mathrm{~s}^{-1}\right)$. With a minimal diffusion coefficient of $0.04 \mathrm{~cm}^{2} \mathrm{~s}^{-1}$ and the same range friction velocities used to calculate particle deposition ( 3 to $0.3 \mathrm{~cm} \mathrm{~s}^{-1}$ ), the characteristic time for loss of vapors to walls was 200 to $2000 \mathrm{~s}$. Although this is fast compared to ventilation it is a relatively small sink compared to condensation on particles. The first-order condensation rate for vapor onto particles, $L_{c o n d}$, was estimated using the Fuchs and Sutugin approach to mass transfer of a gas to a particle in the transition regime. The

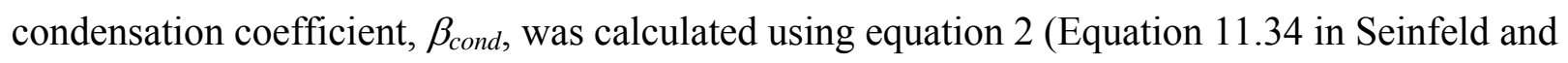
Pandis, 1998) and integrated over the particle size range as shown in equation 1.

$$
\beta_{\text {cond }}\left(D_{p}\right)=2 \pi D_{p} D_{g}\left(\frac{1+K n}{1+1.71 K n+1.33 K n^{2}}\right)
$$

The diffusion coefficient is $D_{g}$, and $K n$ is the Knudsen number. As an example, in experiment POC-MH, the characteristic time for vapor deposition to particles, assuming a diffusion coefficient of $0.04 \mathrm{~cm}^{2} \mathrm{~s}^{-1}$ was $6 \mathrm{~s}$ just after the initial nucleation event and a maximum of $10 \mathrm{~s}$ for the remainder of the experiment. For the range of conditions and vapor diffusivities anticipated in these experiments the time scale for condensation to particles was at least an order of magnitude lower than to walls. 


\subsection{Coagulation sink}

The pseudo first-order rate coefficient for particle loss by coagulation, $L_{\text {coag, }}$, was determined using equation 3 for each scanned particle size distribution.

$$
\begin{aligned}
& L_{\text {coag }}^{*}=\int_{D_{p, \min }}^{D_{p, \max }} \beta_{\text {coag }}\left(D_{p}\right)\left(\frac{d N}{d \log D_{p}}\right) d \log D_{p} \\
& L_{\text {coag }}=\int_{D_{p, \min }}^{D_{p, \max }} L_{\text {coag }}^{*}\left(D_{p}\right)\left(\frac{d N}{d \log D_{p}}\right) d \log D_{p}
\end{aligned}
$$

The size-dependent loss coefficients, $\beta_{\text {coag }}$, for coagulation were calculated using the Fuchs form of the Brownian coagulation coefficient as given in Table 12.1 of Seinfeld and Pandis (1998). Compared with removal by ventilation, coagulation was estimated to contribute $\sim 25 \%$ to total particle number concentration sink immediately after nucleation and $\sim 10 \%$ during later stages.

\section{SOA formation and growth stages}

SMPS data from several characteristic POC experiments are presented in Figure 1. Similar particle formation and growth behavior was exhibited in all experiments, and this behavior is divided into four stages for the present discussion. The stages are illustrated in Figure 2 using experiment AFR-HH as an example. Stage 1 is characterized by an initial nucleation burst occurring immediately after ozone is introduced. The dominant feature of stage 2 is the growth of the particles formed in the initial burst. Stage 3 occurs after ventilation has removed the majority of the particles created in the original nucleation burst; this stage is characterized by the onset of secondary nucleation events. In stage 4 , all of the original particles have left the system and the system has reached a quasi-steady-state. This stage is referred to as quasi-steadystate because the particle size distribution exhibits persistent time-dependent behavior, but of a repetitive or cyclic character. Particle size distribution trends are discussed in $\S 5$ and formation 
and growth dynamics are addressed in $\S 6$.

\section{Size distribution characteristics}

Figure 3 shows examples of the particle size distributions from stage 4 of three experiments. Figure 3a is an example where both the SMPS and OPC data could be combined to produce a good fit. Figure $3 \mathrm{~b}$ shows an experiment where almost the entire distribution was within the range of the SMPS. Figure 3c shows an example of an experiment where the distribution was outside the range of the SMPS but no OPC data were available. In these cases, the characteristics of the upper size range of the distribution were estimated using typical distribution parameters determined from other experiments.

In experiments where both SMPS and OPC data were collected, lognormal distributions were fit to the combined (SMPS and adjusted OPC) size distributions. Three modes were required to fit the data well; using four modes did not significantly improve the fit. Manual fitting of the lognormal distribution parameters was required because, mathematically, the measured distributions were not well constrained owing to missing data at the tails. Modeled distribution parameters (number concentration, $N$; geometric mean diameter, GMD; and geometric standard deviation, GSD) are presented in Table 2.

For experiments without OPC data, the height and central tendency ( $N$ and GMD) for the largest diameter mode could be determined with reasonable confidence from the SMPS data, but the spread (GSD) of the distribution was unknown. Since most fits with both OPC and SMPS data indicated a GSD of 1.4 for the third mode, this value was used to fit the rest of the experiments where only SMPS data were available. Overlaid in each example in Figure 3 is the best-fit 3-mode lognormal distribution.

Table 2 presents the measured and modeled particle data for each of the small chamber 
experiments. Peak total number concentrations during stage 2 were on the order of $10^{5} \mathrm{~cm}^{-3}$ and the particle number concentrations during stage 4 were an order of magnitude lower. Since the vast majority of the particles were smaller than $400 \mathrm{~nm}$, the SMPS provided a fairly accurate measure of the total particle number concentration. Mass concentration $\left(\mathrm{PM}_{1.1}\right)$ ranged from tens to low hundreds of $\mu \mathrm{g} \mathrm{m}^{-3}$, and the stage 4 mass concentration was about half of the value at the peak. Together, the SMPS and OPC captured the full range of particle sizes, but up to half of the mass went undetected when only the SMPS was used.

\subsection{Effect of ozone level and air-exchange rate on mass concentration and yield}

Aerosol yield $(Y)$ was calculated as the total mass concentration of SOA $\left(P M_{1.1, S S}\right)$

formed per mass of VOC consumed $(\triangle V O C)$. Integrated gas-phase samples were taken at steadystate conditions before and after ozone addition, so yields were calculated using steady-state particle mass concentration. For the two experiments (OOD-HL and POC-ML) where the size distribution varied significantly during the steady-state period, the average $P M_{1.1, S S}$ was used to estimate yield.

As shown in Figure 4a, the steady-state mass concentration of SOA was greater at the higher supply ozone level for each of the three products. The relationship between yield and ozone level was similar to the relationship between mass concentration and ozone, although the yield for POC appeared to level off above $\sim 60 \mathrm{ppb}$ ozone, as shown in Figure $4 \mathrm{~b}$. Limonene, $\alpha-$ terpinene, and terpinolene have the highest SOA-forming potential of the terpenes in the tested products (Lee et al., 2006; Koch et al., 2000). The total terpene level (in ppb) introduced was roughly constant from one experiment to the next, but the fraction of terpenes with high SOAforming potential decreased from $100 \%$ in OOD to $65 \%$ in POC to $10 \%$ in AFR. The relative level of SOA production for each household product roughly corresponds to these ratios. 
The yield values agree with other indoor studies. A yield of 10-15\% was estimated from introducing a limonene source into an office ventilated with outdoor air that contained a moderate amount of ozone (Weschler and Shields, 1999). A yield of $\sim 25 \%$ was calculated from particle and terpene data collected from a pine-scented heated air freshener in a chamber study with $50 \mathrm{ppb}$ residual ozone (Liu et al., 2004, yields calculated from Figure 7). A yield of 13\% was reported for limonene injected into an office in which an air-cleaning device that produces ozone as a byproduct was operated (Alshawa et al., 2007).

Relative to the case for AER $=3 \mathrm{~h}^{-1}$, SOA production appears to decrease for POC and OOD and increase for AFR when AER $=1 \mathrm{~h}^{-1}$ (see Figure 4a). However, this plot obscures the relationship between particle production and air-exchange rate. When the steady-state particle concentration is compared to the mass rate of precursor consumption (Figure 4c), it is clear that more SOA is produced per mass of precursor consumed when the air-exchange rate is lowered. This finding is consistent with the expectation that longer reaction times allow for greater oxidation of the ozone reaction products. Several studies have shown that second-generation products of the ozone-limonene reaction make significant contributions to total SOA (Leungsakul et al., 2005; Ng et al., 2006; Zhang et al., 2006). The increased time in the chamber may also allow for more oxidation of the slower-reacting compounds, especially in AFR.

\subsection{Effect of $R H$, order of reagent addition, and ambient seed particles}

The POC-Rev, POC-NOx, and POC-Seed experiments were conducted under the same conditions as POC-HH1 and POC-HH2. Experiment POC-Rev exhibited, as expected, little change in the stage 4 particle characteristics. It also had little effect on the nucleation burst and initial growth, which can be seen by comparing Figures 1a and 1d. The addition of NOx to the supply air did not have an evident effect on SOA formation. In POC-Seed, the seed particle 
number concentration was similar to that in humidified zero-air experiments $\left(\sim 500 \mathrm{~cm}^{-3}\right)$, but the distribution of seed particles was shifted toward larger particles $(\mathrm{GMD}=98 \mathrm{~nm}, \mathrm{GSD}=2.2)$ compared with zero air $(\mathrm{GMD}=30 \mathrm{~nm}, \mathrm{GSD}=1.3)$, resulting in 100 times greater particle mass concentration in the supply air $\left(0.5\right.$ versus $\left.0.005 \mu \mathrm{g} \mathrm{m}^{-3}\right)$. The steady-state particle number and mass concentrations were $\sim 2-3 \times$ and $\sim 35 \%$ higher, respectively, for POC-Seed than POC-HH1.

The POC-Dry experiment was conducted under the same conditions as POC-MH. In running the "dry" experiment, we discovered that the water sparger used to humidify air was the source of seed particles in all 50\% RH experiments. Cocker et al. (2001) reported that moderate $\mathrm{RH}$ tended to increase the overall aerosol yield owing to the hygroscopicity of aerosol-phase organic material, whereas aqueous seed particles containing salts would tend to lower the overall aerosol yield owing to interactions between the salts and the organic material. While the seed particles in our experiments were likely aqueous, it is unknown whether they contained salts.

The effects of removing the seed particles and lowering the $\mathrm{RH}$ cannot be separated in our experiments; the overall effect was to lower the particle number and mass concentration (see Figures $1 \mathrm{~b}$ and $1 \mathrm{c})$. The number and mass particle concentrations in the supply air for the POCDry experiment were $<5 \mathrm{~cm}^{-3}$ and $<0.001 \mu \mathrm{g} \mathrm{\textrm {m } ^ { - 3 }}$, respectively, and corresponding concentrations in POC-MH were $380 \mathrm{~cm}^{-3}(\mathrm{GMD}=24 \mathrm{~nm}, \mathrm{GSD}=1.3)$ and $0.005 \mu \mathrm{g} \mathrm{m}^{-3}$.

\section{Particle formation and growth characteristics}

\subsection{Cycle of particle formation and growth}

Figure 1f shows experimental results where a repeated cycle of particle formation and growth occurs in stages 3 and 4 . The balance between new particle formation and growth of existing particles in the chamber can be plausibly explained as follows. As particles grow by condensation, they are also are removed by ventilation, reducing the total surface area available 
for condensation. Condensable vapor then accumulates until a burst of nucleation occurs that significantly lowers the vapor concentration. These newly formed particles grow while continuing to be removed from the chamber by ventilation, again reducing the surface area available for condensation, and the cycle repeats. The balance between nucleation and growth is most clearly visible in the low AER experiments, as illustrated by the repeated appearance of plumes in Figure $1 \mathrm{f}$ for experiment POC-HL. In contrast, in the higher AER experiments, particles are so rapidly ventilated out of the system that new particle formation by nucleation seems to occur almost constantly. The plumes of these nucleation events are compressed to a timescale similar to that of the SMPS measurements, giving the appearance of a steady-state particle size distribution. An example of this behavior is illustrated in Figure 1a for experiment POC-HH. Experiment POC-MH exhibited behavior between these two extremes, as shown in Figure $1 \mathrm{~b}$. Trends in particle mass and number concentration support this description. In experiments where the particle behavior is dynamic, such as in POC-HL (Figure 1f) and OOD$\mathrm{HL}$, the mass concentration and GMD increase and the number concentration decreases after each nucleation event.

This process of condensable vapor accumulation and subsequent nucleation burst is also thought to be responsible for the "fingers," or separate peaks in the size distribution that appear in stage 2 of every experiment. Once the initial burst of particles is formed, some are removed by ventilation or there is otherwise a build up of condensable vapor that cannot be accommodated by condensation on the existing particles and a small new burst occurs, creating a thin plume. Peaks grow by condensation at rates similar to those around it, and it is not until enough particle surface area is removed by ventilation that this phenomenon is halted.

The rate of decay of particle number concentration in the chamber following the initial 
burst provides additional evidence of persistent particle nucleation. After the initial nucleation burst, the decay rate of the particle number concentration is less than the loss rate expected from ventilation alone. Figure 5 compares the observed pseudo first-order loss rate of particle number concentration with the air-exchange rate for experiment POC-MH. The apparent loss rate was $2.5 \mathrm{~h}^{-1}$ while the AER was $3.0 \mathrm{~h}^{-1}$. We infer that nucleation must be occurring to provide a fresh source of new particles that offsets some of the removal by ventilation. In this experiment, about 40 minutes after ozone was introduced (at 16:25), the particle loss rate slowed, rebounded slightly and then settled at an effectively constant level. The inflection corresponds to the onset of stage 3, with the occurrence of distinct new nucleation events, as can be seen in Figure 1b. New particle formation occurred because not enough of the original particles remained in the chamber to accommodate the condensable vapor being formed. The dip in the particle number concentration is the result of two effects. First, the originally created particles have grown so large that they are no longer counted by the SMPS. Second, so long as the large particles from the initial burst remain present, their growth in surface area means that fewer particles are required to accommodate the flow of condensable mass as time progresses.

The balance between condensation and nucleation is also evident in the OPC data. As shown in Figure 2, the number concentration of particles in the $0.62-0.89 \mu \mathrm{m}$ size bin stagnates as secondary nucleation starts at the onset of stage 3 . The stagnation occurs because the condensational growth is now apportioned between the numerous newly formed particles and the small number of residual large particles. Temporary stagnation in this size bin at the onset of secondary nucleation is seen in all experiments for which OPC data were collected, and the effect was more pronounced for experiments with higher particle concentrations.

\subsection{Nucleation subsequent to the initial event}


The nucleation events subsequent to the initial burst do not produce the large number concentrations of particles that were created in the initial event. There are two likely reasons for this depressed nucleation intensity. First, there is not as much condensable material in the system in stages two through four as there was when ozone was first introduced. When ozone first enters the chamber, the concentration of terpenes in the system is at its highest; for the remainder of each experiment, ozone only can react with the residual terpene concentrations. Second, there are many preexisting particles in the system after the initial burst, and some of the condensable material contributes to particle growth rather than to nucleation.

The inference that nucleation is occurring in stages 3 and 4 , rather than just growth of seed particles, is reinforced by two observations: the particles present in the third and fourth stages are smaller than those present in the supply air; and the number concentration of particles in the chamber persists at a level that is orders of magnitude higher than the number concentration of particles in the supply air. It seems very unlikely that so many seed particles smaller than the lower limit of the SMPS $(\sim 8 \mathrm{~nm})$ would exist in the supply air and could therefore be responsible for the appearance of smaller particles in the system through growth.

At steady state, the particle nucleation rate can be evaluated from a number balance. The only significant source contributing to the total particle number concentration in the chamber, $P_{N}$, is nucleation, and the dominant sink is removal by ventilation, so a material balance is:

$$
\frac{d P_{N}}{d t}=R_{N}-\lambda P_{N} \quad R_{N}=\lambda P_{N, S S}
$$

At steady state, the rate of nucleation, $R_{N}$, can be estimated as the chamber air-exchange rate, $\lambda$, times the steady-state particle number concentration, $P_{N, S s}$. The number of particles in the supply air is negligible compared to the number of particles when ozone and terpenes are present, and thus air supply is not included as a source. For example, in experiment POC-MH, the supply air 
contained a particle concentration of $350 \mathrm{~cm}^{-3}$, whereas the stage 4 chamber concentration was $24,000 \mathrm{~cm}^{-3}$. In this experiment, the nucleation rate was estimated to be $20 \mathrm{~cm}^{-3} \mathrm{~s}^{-1}$. Multiplying by the volume of the chamber $(198 \mathrm{~L})$ gives a total particle generation rate of $4 \times 10^{6} \mathrm{~s}^{-1}$. For comparison, in a study in a lab room where limonene was released as a result of peeling oranges in the presence of $\sim 20 \mathrm{ppb}$ ozone, the calculated particle nucleation rate throughout the room was considerably smaller, $\sim 10^{5} \mathrm{~s}^{-1}$ (Vartiainen et al., 2006).

Similarly, a balance on particle mass concentration, $P_{M}$, considers formation from condensation of reaction products, balanced by removal by means of ventilation:

$$
\frac{d P_{M}}{d t}=R_{C}-\lambda P_{M} \quad R_{C}=\lambda P_{M, S S}
$$

Again, at steady state, the production rate of condensed material, $R_{C}$, must approximately equal the chamber air-exchange rate, $\lambda$, times the total measured steady-state particle mass concentration, $P_{M, S S}$. The mass concentration of particles in the supply air is negligible compared with the concentration when ozone and terpenes are present, and thus is not included as a source. For example, in experiment POC-MH, the supply air contained $0.005 \mu \mathrm{g} \mathrm{m}^{-3}$ and the stage 4 concentration in the chamber was $76 \mu \mathrm{g} \mathrm{m}^{-3} . R_{C}$ represents only a fraction of the total production rate of reaction products, since some of the reaction products may persist in the gas phase or deposit on chamber surfaces. For the POC-MH experiment, the mass production rate of the particle-phase condensed material was $3.8 \mu \mathrm{g} \mathrm{m}^{-3} \mathrm{~min}^{-1}$. The steady-state particle nucleation and mass production rates calculated in this way for all experiments using the steady-state number and mass concentrations from Table 2 and the AER from Table 1 were in the range $1-23 \mathrm{~cm}^{-3} \mathrm{~s}^{-1}$ and $1-13 \mu \mathrm{g} \mathrm{m}^{-3} \mathrm{~min}^{-1}$, respectively, as reported in Table 2.

During stage 4 in many experiments, the mean particle size tended to increase slightly over several hours (see Figure 1d). In smog-chamber experiments where ozone is reacted with 
terpenes, as condensable matter is formed, the GMD of the particles increases; however, in our flow-through system, where particles are continuously being created and swept out of the chamber, the explanation for growth of the GMD of the aerosol distribution is not apparent.

\subsection{Modeling total particle mass formation}

Can a simple mechanistic model be used to describe the rate of increase in particle mass concentration during the initial parts of these experiments? The OOD experiments were used for this exercise because OOD only contains one reactive compound, d-limonene. We used a numerical approximation to solve coupled differential equations for the species considered: ozone $\left[\mathrm{O}_{3}\right]$, limonene $[L]$, and secondary particle mass $[S O A]$ (equations 6-8).

$$
\begin{aligned}
& \frac{d\left[\mathrm{O}_{3}\right]}{d t}=\lambda\left[\mathrm{O}_{3}\right]_{\text {supply }}-\lambda\left[\mathrm{O}_{3}\right]-k_{\mathrm{O}_{3}}\left[\mathrm{O}_{3}\right][L] \\
& \frac{d[L]}{d t}=\lambda[L]_{\text {supply }}-\lambda[L]-k_{\mathrm{O}_{3}}\left[\mathrm{O}_{3}\right][L] \\
& \frac{d[S O A]}{d t}=\lambda[S O A]_{\text {supply }}-\lambda[S O A]+Y k_{O_{3}}\left[O_{3}\right][L]
\end{aligned}
$$

Units of ppb were used for ozone and limonene concentrations in equations 6 and 7, but the limonene concentration was converted to units of $\mu \mathrm{g} \mathrm{m}^{-3}$ for use in equation 8 . The SOA concentration was also expressed in units of $\mu \mathrm{g} \mathrm{m}^{-3}$. The reaction rate for ozone and limonene, $k_{O 3}$, was set to the experimentally determined value of $5.16 \times 10^{-6} \mathrm{ppb}^{-1} \mathrm{~s}^{-1}$ (Hakola et al., 1994). The yield, $Y$, was set to the value determined in the present study (values shown in Figure $4 \mathrm{~b}$ ). In the two cases in which the AER was relatively high (OOD-HH and OOD-MH), this model captured the overall shape of the increase in total particle mass concentration after the initial nucleation burst, but slightly underestimated particle mass. However, in the low AER case (POC-HL), the model substantially underpredicted both the total mass of SOA formed and the

rate of formation (Figure 6). While the yield value taken from the experiment is an overall value 
that incorporates all factors contributing to SOA formation, the model may underpredict mass formation because it considers only reactions of ozone and limonene. Other factors that may contribute to SOA mass are uptake of water by the hygroscopic SOA (Cocker et al., 2001) and condensation of "second-generation" oxidation products.

Ozone reaction with limonene produces first-generation oxidation products and the hydroxyl radical (Aschmann et al., 2002). Ozone and $\mathrm{OH}$ react with these oxidation products to form second-generation products and so on. Subsequent oxidation products can be even less volatile than first-generation products leading to increased SOA mass (Leungsakul et al., 2005; $\mathrm{Ng}$ et al., 2006; Zhang et al., 2006). We postulate that in the low AER case, the secondary oxidation products formed from the ozone-limonene reaction have additional time to react, forming even lower volatility products, which tend to condense and increase the total mass of SOA formed. This inference is consistent with the lower ozone and $\mathrm{OH}$ radical concentrations previously reported for the low AER experiments, as compared with those determined for the same conditions, but with higher AER (Destaillats et al., 2006).

\section{Conclusions}

In this study, a series of chamber experiments was used to characterize the dynamics of particle formation and growth from ozone reactions with terpene-containing vapors from consumer products under indoor-relevant conditions. The particles formed were in the ultrafine and accumulation modes $(<1.1 \mu \mathrm{m})$. Particles were measured with an SMPS $(10 \mathrm{~nm}$ to $400 \mathrm{~nm})$ and an OPC ( 0.1 to $1.1 \mu \mathrm{m})$, and data from the two instruments were aligned by means of adjusting the OPC bin bounds by fits informed by an assumed composition of the aerosol. The mass concentrations of ultrafine and accumulation mode particles $\left(\mathrm{PM}_{1.1}\right)$ formed by ozone reaction with terpene-containing cleaning products ranged from the tens to low-hundreds of $\mu \mathrm{g}$ 
$\mathrm{m}^{-3}$. For comparison, yearly maximum 24 -hour ambient $\mathrm{PM}_{2.5}$ concentrations are in the same range (USEPA, 2008). Hence, relative to health-based standards, this evidence suggests that indoor reactions between ozone and terpenes can be a significant source of particles, warranting further study of potential exposure-related health effects.

In each of the 16 experiments conducted, a burst of particle formation by nucleation occurred immediately after ozone addition. This burst was followed by a period characterized predominantly by condensational growth of the nucleated particles. The system then evolved through a third stage to a fourth during which particle nucleation and growth persisted under steady state or cyclic conditions for the remainder of the experiment. At higher air-exchange rates, the particle surface area was reduced rapidly as particles were swept out of the chamber, and nucleation seemed to occur constantly, whereas in the lower AER experiments an oscillating dynamic balance between formation and growth was exhibited. Mass and yield of SOA were observed to increase with increasing ozone level for the range of ozone levels likely to be encountered under normal indoor conditions. More SOA was formed per unit precursor consumed when the air-exchange rate was lowered. The additional SOA formation may be a result second-generation oxidation.

In any real environment there would likely be much greater spatial heterogeneity than in these small-chamber experiments. Nevertheless, SOA formation and growth has been measured in realistic settings and has exhibited similar characteristics (size distribution and growth dynamics) to the SOA production measured in these more controlled experiments. Although information about particle formation and growth can be ascertained from instruments with lower size and time resolution, certainly instruments with higher resolution and lower limits of particle size detection provide a clearer picture of the particle dynamic processes. Studies such as the one 
presented here help to elucidate the distribution and evolution of particles that people are likely exposed to when vapors from terpene-containing cleaning products or air fresheners are simultaneously present with ozone indoors.

\section{Acknowledgments}

The California Air Resources Board (Contract No. 01-336) provided financial support for the experimental work on which this paper is based. The statements and conclusions in this report are those of the researchers and not necessarily those of the California ARB. The mention of commercial products, their source, or their use in connection with material reported herein is not to be construed as actual or implied endorsement of such products. Additional support in the form of a graduate fellowship for BKC from the National Science Foundation is gratefully acknowledged. All work at LBNL was conducted under US DOE Contract No. DE-AC02$05 \mathrm{CH} 11231$.

\section{References}

Alshawa, A., Russell, A.R., Nizkorodov, S.A., 2007. Kinetic analysis of competition between aerosol particle removal and generation by ionization air purifiers. Environmental Science \& Technology 41, 2498-2504.

Aschmann, S.M., Arey, J., Atkinson, R., 2002. OH radical formation from the gas-phase reactions of $\mathrm{O}_{3}$ with a series of terpenes. Atmospheric Environment 36, 4347-4355.

Asgharian, B., Price, O.T., 2007. Deposition of ultrafine (NANO) particles in the human lung. Inhalation Toxicology 19, 1045-1054.

Cocker III, D.R., Clegg, S.L., Flagan, R.C., Seinfeld, J.H., 2001. The effect of water on gasparticle partitioning of secondary organic aerosol. Part I: $\alpha$-pinene/ozone system.

Atmospheric Environment 35, 6049-6072.

Destaillats, H., Lunden, M.M., Singer, B.C., Coleman, B.K., Hodgson, A.T., Weschler, C.J., Nazaroff, W.W., 2006. Indoor secondary pollutants from household product emissions in the 
presence of ozone: a bench-scale chamber study. Environmental Science \& Technology 40, 4421-4428.

Dick, W.D., Ziemann, P.J., McMurry, P.H., 2007. Multiangle light-scattering measurements of refractive index of submicron atmospheric particles. Aerosol Science and Technology 41, 549-569.

Hakola, H., Arey, J., Aschmann, S.M., Atkinson, R., 1994. Product formation from the gas-phase reactions of $\mathrm{OH}$ radicals and $\mathrm{O}_{3}$ with a series of monoterpenes. Journal of Atmospheric Chemistry 18: 75-102.

Hand, J.L., Kreidenweis, S.M., 2002. A new method for retrieving particle refractive index and effective density from aerosol size distribution data. Aerosol Science and Technology 36, 1012-1026.

Hubbard, H.F., Coleman, B.K., Sarwar, G., Corsi, R.L., 2005. Effects of an ozone-generating air purifier on indoor secondary particles in three residential dwellings. Indoor Air 15, 432-444.

Khlystov, A., Stanier, C., Pandis, S.N., 2004. An algorithm for combining electrical mobility and aerodynamic size distributions data when measuring ambient aerosol. Aerosol Science and Technology 38 (Suppl. 1), 229-238.

Koch, S. Winterhalter, R., Uherek, E., Kolloff, A., Neeb, P., Moortgat, G.K., 2000. Formation of new particles in the gas-phase ozonolysis of monoterpenes. Atmospheric Environment 34, 4031-4042.

Lai, A.C.K., Nazaroff, W.W., 2000. Modeling indoor particle deposition from turbulent flow onto smooth surfaces. Journal of Aerosol Science 31, 463-476.

Lee, A., Goldstein, A.H., Keywood, M.D., Gao, S., Varutbangkul, V., Bahreini, R., Ng, N.L., Flagan, R.C., Seinfeld, J.H., 2006. Gas-phase products and secondary aerosol yields from the ozonolysis of ten different terpenes. Journal of Geophysical Research-Atmospheres 111, D07302.

Leungsakul, S., Jaoui, M., Kamens, R.M., 2005. Kinetic mechanism for predicting secondary organic aerosol formation from the reaction of d-limonene with ozone. Environmental Science \& Technology 39, 9583-9594. 
Liu, X., Mason, M., Krebs, K., Sparks, L., 2004. Full-scale chamber investigation and simulation of air freshener emissions in the presence of ozone. Environmental Science \& Technology $38,2802-2812$.

Long, C.M., Suh, H.H., Koutrakis, P., 2000. Characterization of indoor particle sources using continuous mass and size monitors. Journal of the Air \& Waste Management Association 50, 1236-1250.

Nazaroff, W.W., Weschler, C.J., 2004. Cleaning products and air fresheners: exposure to primary and secondary air pollutants. Atmospheric Environment 38, 2841-2865.

Nazaroff, W.W., 2008. Inhalation intake fraction of pollutants from episodic indoor emissions. Building and Environment 43, 269-277.

Ng, N.L., Kroll, J.H., Keywood, M.D., Bahreini, R., Varutbangkul, V., Flagan, R.C., Seinfeld, J.H., Lee, A., Goldstein, A.H., 2006. Contribution of first- versus second-generation products to secondary organic aerosols formed in the oxidation of biogenic hydrocarbons.

Environmental Science \& Technology 40, 2283-2297.

Oberdörster, G., 2001. Pulmonary effects of inhaled ultrafine particles. International Archives of Occupational and Environmental Health 74, 1-8.

Peters, A., Wichmann, H.E., Tuch, T., Heinrich, J., Heyder, J., 1997. Respiratory effects are associated with the number of ultrafine particles. American Journal of Respiratory and Critical Care Medicine 155, 1376-1383.

Pope, C.A., Dockery, D.W., 2006. Health effects of fine particulate air pollution: lines that connect. Journal of the Air \& Waste Management Association 56, 709-742.

Sarwar, G., Corsi, R., Allen, D., Weschler, C., 2003. The significance of secondary organic aerosol formation and growth in buildings: experimental and computational evidence. Atmospheric Environment 37, 1365-1381.

Sarwar, G., Olson, D.A., Corsi, R.L., Weschler, C.J., 2004. Indoor fine particles: the role of terpene emissions from consumer products. Journal of the Air \& Waste Management Association 54, 367-377.

Seinfeld, J.H., Pandis, S.N., 1998. Atmospheric chemistry and physics: from air pollution to 
climate change. Wiley, New York.

Singer, B.C., Coleman, B.K., Destaillats, H., Hodgson, A.T., Lunden, M.M., Weschler, C.J., Nazaroff, W.W., 2006a. Indoor secondary pollutants from cleaning product and air freshener use in the presence of ozone. Atmospheric Environment 40, 6696-6710.

Singer, B.C., Destaillats, H., Hodgson, A.T., Nazaroff, W.W., 2006b. Cleaning products and air fresheners: emissions and resulting concentrations of glycol ethers and terpenoids. Indoor Air 16, 179-191.

Turpin, B.J., Lim, H.J., 2001. Species contributions to PM2.5 mass concentrations: revisiting common assumptions for estimating organic mass. Aerosol Science \& Technology 35, 602610.

USEPA (United States Environmental Protection Agency), 2008. Criteria air pollutants monitor values report for $\mathrm{PM}_{2.5}$ in United States in 2007. (http://www.epa.gov/air/data/help/hmonvals.html?us USA United\%20States)

Vartiainen, E., Kulmala, M., Ruuskanen, T.M., Taipale, R., Rinne, J., Vehkamaki, H., 2006. Formation and growth of indoor air aerosol particles as a result of D-limonene oxidation. Atmospheric Environment 40, 7882-7892.

Wainman, T., Zhang, J.F., Weschler, C.J., Lioy, P.J., 2000. Ozone and limonene in indoor air: a source of submicron particle exposure. Environmental Health Perspectives 108, 1139-1145.

Weschler, C.J., 2000. Ozone in indoor environments: concentration and chemistry. Indoor Air $10,269-288$.

Weschler, C.J., Shields, H.C., 1999. Indoor ozone/terpene reactions as a source of indoor particles. Atmospheric Environment 33, 2301-2312.

Weschler, C.J., Shields, H.C., 2003. Experiments probing the influence of air-exchange rates on secondary organic aerosols derived from indoor chemistry. Atmospheric Environment 37, 5621-5631.

Yeh, H.C., Cuddihy, R.G., Phalen, R.F., Chang, I.Y., 1996. Comparisons of calculated respiratory tract deposition of particles based on the proposed NCRP model and the new ICRP66 model. Aerosol Science and Technology 25, 134-140. 
Zhang, J., Huff Hartz, K.E., Pandis, S.N., Donahue, N.M., 2006. Secondary organic aerosol formation from limonene ozonolysis: homogeneous and heterogeneous influences as a function of $\mathrm{NO}_{\mathrm{x}}$. Journal of Physical Chemistry A 110, 11053-11063. 


\section{Figure Captions}

Figure 1. Particle size-distribution evolution as measured with an SMPS for six POC experiments. The y-axis indicates particle diameter, $D_{p}(n m)$, the $x$-axis represents time (with tick marks indicating 30-min increments) and the shading indicates the count-based particle size distribution, $\mathrm{dN} / \mathrm{d}\left(\log \mathrm{D}_{\mathrm{p}}\right)\left(\mathrm{cm}^{-3}\right)$.

Figure 2. Example of the characteristic stages of particle formation and growth in chamber experiments, illustrated for experiment AFR-HH. Stage 1 is characterized by a sudden nucleation burst when ozone is added to a steady-state level of product vapor. Stage 2 is characterized by the growth of particles from the initial nucleation burst. In stage 3 nucleation resumes but particles from the initial nucleation event are still present. In stage 4 a steady or oscillating particle concentration is achieved. The color scale for $\mathrm{dN} / \mathrm{d}\left(\log \mathrm{D}_{\mathrm{p}}\right)$ in the lower frame is the same as in Figure 1.

Figure 3. Size distributions measured with SMPS and OPC and fit using the sum of three lognormal distributions. The $\mathrm{dN} / \mathrm{d}\left(\log \mathrm{D}_{\mathrm{p}}\right)$ scale has units of $\mathrm{cm}^{-3}$.

Figure 4. Effect of ozone level and air-exchange rate on steady-state fine particle $\left(\mathrm{PM}_{1.1}\right)$ mass concentration and yield. The lines are drawn to guide the eye. Solid symbols correspond to an air-exchange rate (AER) of $3 \mathrm{~h}^{-1}$ and hollow symbols indicate AER $=1 \mathrm{~h}^{-1}$.

Figure 5. Comparison of the measured change in particle number concentration with loss expected from ventilation alone for experiment POC-MH during stage 2 . The timedependent total SMPS particle number concentration is shown with a solid line, and lines are superimposed for apparent loss rate (dash) and loss expected from ventilation alone (dash-dot).

Figure 6. Modeled and measured particle mass concentrations vs. time for three experiments using the orange-oil degreaser. The sudden decrease in particle mass results from growth of the largest particles out of the size range of the SMPS. 
Table 1. Experimental conditions. ${ }^{\text {a }}$

\begin{tabular}{|c|c|c|c|c|c|c|c|}
\hline Exp. ID & $\begin{array}{c}\text { Ozone } \\
\text { level }\end{array}$ & $\begin{array}{l}\text { Air- } \\
\text { exchange } \\
\text { rate }\end{array}$ & $\begin{array}{c}\text { Supply } \\
\text { ozone } \\
\text { level } \\
\text { (ppb) }\end{array}$ & $\begin{array}{c}\text { Residual } \\
\text { ozone } \\
\text { level } \\
\text { (ppb) }\end{array}$ & $\begin{array}{c}\text { Air- } \\
\text { exchange } \\
\text { rate }\left(\mathrm{h}^{-1}\right)\end{array}$ & $\begin{array}{c}\text { Supply } \\
\text { terpene } \\
\text { level } \\
\text { (ppb) }\end{array}$ & $\begin{array}{c}\text { Residual } \\
\text { terpene } \\
\text { level } \\
\text { (ppb) }\end{array}$ \\
\hline \multicolumn{8}{|c|}{ Orange-oil based degreaser (OOD) } \\
\hline OOD-HH & High & High & 137 & 21 & 3.0 & 643 & 518 \\
\hline OOD-HL & High & Low & 136 & 7 & 1.0 & 738 & 588 \\
\hline OOD-MH & Moderate & High & 61 & 11 & 3.1 & 586 & 528 \\
\hline \multicolumn{8}{|c|}{ Heated-oil air freshener (AFR) } \\
\hline AFR-HH & High & High & 126 & 18 & 3.0 & 623 & 492 \\
\hline AFR-HL & High & Low & 127 & 4 & 1.0 & 859 & 658 \\
\hline AFR-MH & Moderate & High & 63 & 7 & 3.0 & 596 & 506 \\
\hline \multicolumn{8}{|c|}{ Pine-oil based cleaner (POC) } \\
\hline POC-VH & Very high & High & 253 & 25 & 3.0 & 716 & 439 \\
\hline POC-HH1 & High & High & 131 & 13 & 3.0 & 771 & 560 \\
\hline POC-HH2 & High & High & 121 & 12 & 3.0 & 692 & 531 \\
\hline POC-HL & High & Low & 130 & 8 & 1.0 & 735 & 599 \\
\hline POC-MH & Moderate & High & 65 & 2 & 3.0 & 734 & 673 \\
\hline POC-LH & Low & High & 29 & 0 & 3.1 & 566 & 540 \\
\hline POC-NOx & High & High & 139 & 8 & 3.0 & 817 & 615 \\
\hline POC-Rev & High & High & 120 & - & 3.0 & - & - \\
\hline POC-Seed & High & High & 125 & - & 3.0 & - & - \\
\hline POC-Dry & Moderate & High & 63 & - & 3.0 & 558 & 512 \\
\hline
\end{tabular}

${ }^{a}$ For experimental identification, the pre-dash letters denote the cleaning product and the postdash letters denote some key aspect of experimental conditions, as follows: "HH" indicates high ozone level ( $\sim 130 \mathrm{ppb}$ at the inlet) and high air-exchange rate (AER $\left.=3 \mathrm{~h}^{-1}\right)$; "HL" indicates high ozone level and low AER $\left(1 \mathrm{~h}^{-1}\right)$; and "MH" indicates moderate ozone level ( $\sim 60 \mathrm{ppb}$ at the inlet) and high AER. Extra experiments were conducted with POC: "VH" denotes very high supply ozone (253 ppb at the inlet) and high AER; "HH1" and "HH2" are replicate experiments under HH conditions; "LH" indicates low ozone level (29 ppb at the inlet) and high AER. See text for a description of the remaining four POC experiments. 
Table 2. Secondary aerosol size distribution parameters and formation rates.

\begin{tabular}{|c|c|c|c|c|c|c|c|c|c|c|c|c|c|c|c|c|c|c|c|}
\hline \multirow{4}{*}{ Exp. ID } & \multicolumn{6}{|c|}{ Measured } & \multicolumn{13}{|c|}{ Modeled } \\
\hline & \multirow{3}{*}{$\begin{array}{c}\text { Peak } \\
\text { number } \\
\text { conc. } \\
\left(10^{5} \mathrm{~cm}^{-3}\right)\end{array}$} & \multirow{2}{*}{\multicolumn{2}{|c|}{$\begin{array}{l}\text { Peak mass conc. } \\
\quad\left(\mu \mathrm{g} \mathrm{m}^{-3}\right)\end{array}$}} & \multirow{3}{*}{$\begin{array}{c}\text { Steady- } \\
\text { state } \\
\text { number } \\
\text { conc. } \\
\left(10^{5} \mathrm{~cm}^{-3}\right) \\
\end{array}$} & \multirow{2}{*}{\multicolumn{2}{|c|}{$\begin{array}{l}\text { Steady-state mass } \\
\text { conc. }\left(\mu \mathrm{g} \mathrm{m}^{-3}\right)\end{array}$}} & \multicolumn{9}{|c|}{ Lognormal fit parameters } & \multirow{2}{*}{\multicolumn{2}{|c|}{$\begin{array}{l}\text { Steady-state } \\
\text { mass conc. } \\
\left(\mu \mathrm{g} \mathrm{m}^{-3}\right)\end{array}$}} & \multirow{3}{*}{$\begin{array}{c}\mathbf{R}_{\mathrm{N}, \mathrm{ss}} \\
\left(\mathrm{cm}^{-3} \mathbf{s}^{-1}\right)\end{array}$} & \multirow{3}{*}{$\underset{\underset{\left.\text { min }^{-1}\right)}{\mathbf{R}_{\mathrm{M}, \mathrm{SS}}}}{\mathbf{- 1}}$} \\
\hline & & & & & & & \multicolumn{3}{|c|}{ Mode 1} & \multicolumn{3}{|c|}{ Mode 2} & \multicolumn{3}{|c|}{ Mode 3} & & & & \\
\hline & & $\mathbf{P M}_{0.4}$ & $\mathbf{P M}_{1.1}$ & & $\mathbf{P M}_{0.4}$ & $\mathbf{P M}_{1.1}$ & $\begin{array}{c}\mathbf{N} \\
\left(\mathrm{cm}^{-3}\right)\end{array}$ & $\begin{array}{l}\text { GMD } \\
(\mathrm{nm})\end{array}$ & GSD & $\begin{array}{c}\mathbf{N} \\
\left(\mathrm{cm}^{-3}\right)\end{array}$ & $\begin{array}{l}\text { GMD } \\
(\mathrm{nm})\end{array}$ & GSD & $\begin{array}{c}\mathbf{N} \\
\left(\mathrm{cm}^{-3}\right)\end{array}$ & $\begin{array}{l}\text { GMD } \\
(\mathrm{nm})\end{array}$ & GSD & $\mathbf{P M}_{0.4}$ & $\mathbf{P M}_{1.1}$ & & \\
\hline OOD-HH & 1.4 & 229 & - & 0.18 & 105 & - & 2300 & 48 & 1.6 & 7000 & 135 & 1.6 & 8700 & 314 & 1.4 & 126 & 259 & 15 & 13 \\
\hline OOD-HL ${ }^{*}$ & 0.8 & 192 & - & 0.13 & 71 & - & 1500 & 40 & 1.5 & 5000 & 105 & 1.5 & 6000 & 310 & 1.4 & 87 & 162 & 4 & 3 \\
\hline OOD-HL ${ }^{*}$ & & & & 0.10 & 87 & - & 1500 & 70 & 1.6 & 2500 & 140 & 1.5 & 7500 & 330 & 1.4 & 99 & 243 & 3 & 4 \\
\hline OOD-MH & 0.6 & 75 & - & 0.13 & 53 & - & 2200 & 45 & 1.6 & 5700 & 123 & 1.6 & 4700 & 265 & 1.4 & 63 & 92 & 11 & 5 \\
\hline AFR-HH & 0.4 & 51 & 93 & 0.08 & 33 & 80 & 2200 & 45 & 1.6 & 3200 & 125 & 1.5 & 2700 & 280 & 1.35 & 39 & 54 & 7 & 3 \\
\hline AFR-HL & 0.9 & 90 & 146 & 0.05 & 37 & 110 & 1300 & 55 & 1.7 & 1700 & 140 & 1.5 & 3300 & 300 & 1.4 & 44 & 83 & 1 & 1 \\
\hline AFR-MH & 0.2 & 21 & 35 & 0.07 & 15 & 29 & 1600 & 35 & 1.55 & 2900 & 100 & 1.6 & 1800 & 222 & 1.4 & 18 & 21 & 6 & 1 \\
\hline POC-VH & 3.6 & 306 & 435 & 0.16 & 107 & 215 & 3000 & 45 & 1.6 & 5000 & 130 & 1.6 & 7500 & 315 & 1.4 & 104 & 220 & 13 & 11 \\
\hline POC-HH1 & 2.3 & 174 & 273 & 0.12 & 67 & 115 & 2500 & 48 & 1.6 & 4500 & 140 & 1.6 & 4700 & 316 & 1.4 & 72 & 147 & 10 & 7 \\
\hline POC-HH2 & 2.4 & 162 & - & 0.11 & 66 & - & 3000 & 60 & 1.7 & 3080 & 138 & 1.5 & 6000 & 295 & 1.4 & 79 & 144 & 9 & 7 \\
\hline POC-HL ${ }^{*}$ & 1.6 & 102 & - & 0.14 & 58 & - & 1500 & 80 & 1.7 & 5000 & 140 & 1.4 & 6000 & 243 & 1.3 & 69 & 75 & 4 & 1 \\
\hline POC-HL ${ }^{*}$ & & & & 0.10 & 75 & - & 3000 & 70 & 1.7 & 1400 & 211 & 1.35 & 4900 & 305 & 1.3 & 78 & 111 & 3 & 2 \\
\hline POC-MH & 1.2 & 57 & - & 0.24 & 50 & - & 1300 & 25 & 1.5 & 13000 & 75 & 1.7 & 7000 & 223 & 1.4 & 64 & 76 & 20 & 4 \\
\hline POC-LH & 0.5 & 12 & 35 & 0.1 & 11 & 19 & 4000 & 42 & 1.65 & 3800 & 110 & 1.56 & 1400 & 182 & 1.45 & 14 & 15 & 8 & 1 \\
\hline POC-NOx & 1.8 & 146 & 215 & 0.14 & 64 & 185 & 2900 & 37 & 1.55 & 5500 & 115 & 1.6 & 5000 & 300 & 1.4 & 70 & 130 & 12 & 7 \\
\hline POC-Rev & 1.9 & 149 & 220 & 0.12 & 67 & 175 & 2000 & 40 & 1.6 & 4500 & 120 & 1.6 & 6000 & 295 & 1.4 & 80 & 145 & 10 & 7 \\
\hline POC-Seed & 3.2 & 141 & 225 & 0.28 & 100 & 212 & 9000 & 55 & 1.75 & 7000 & 105 & 1.5 & 15000 & 225 & 1.5 & 130 & 200 & 23 & 10 \\
\hline POC-Dry & 0.9 & 62 & - & 0.06 & 31 & - & 1300 & 60 & 1.8 & 2000 & 130 & 1.5 & 3000 & 275 & 1.4 & 38 & 60 & 5 & 3 \\
\hline
\end{tabular}

Indicates experiments where the size distribution varied significantly during stage 4 and two sets of distribution parameters are given to show maximum and minimum values. 


\section{Figure 1}

(a) POC-HH

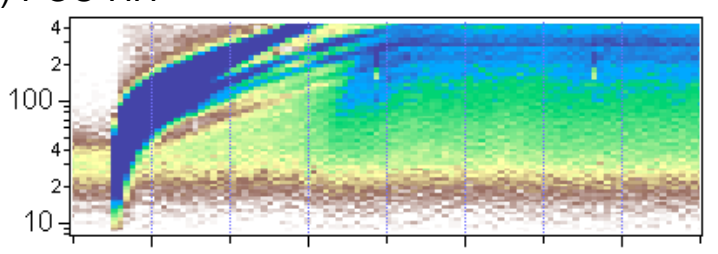

(b) $\mathrm{POC}-\mathrm{MH}$

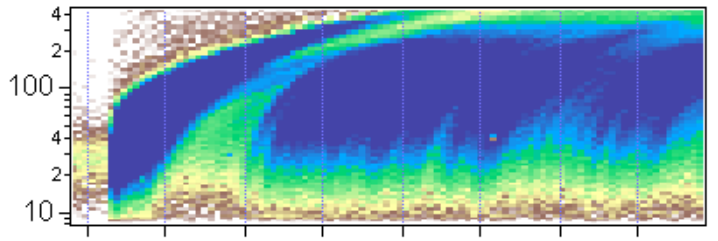

(c) POC-Dry

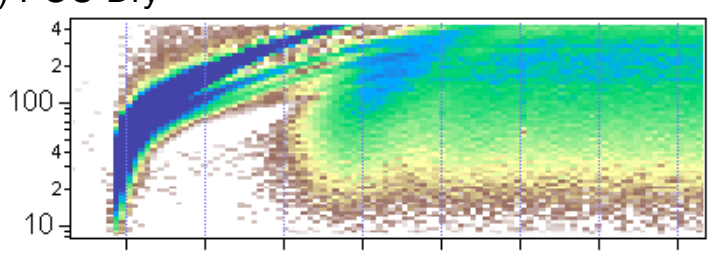

(d) POC-Rev

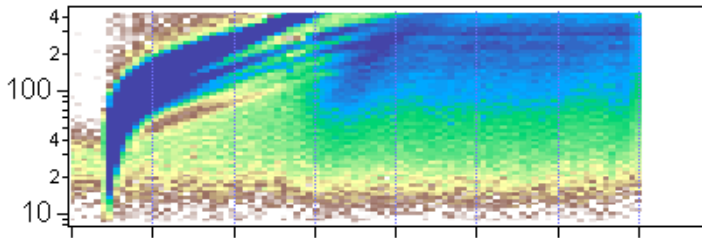

(e) POC-Seed

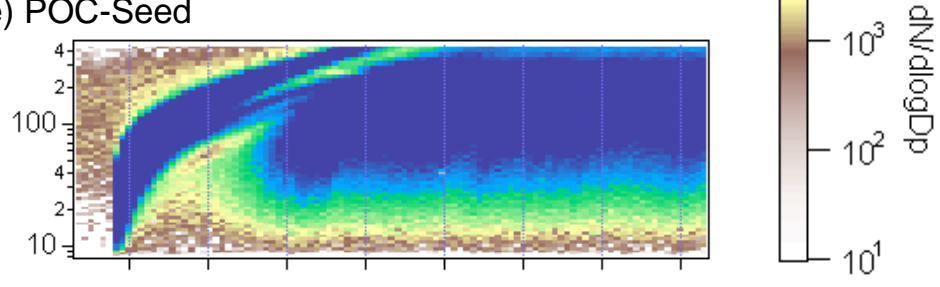

(f) $\mathrm{POC}-\mathrm{HL}$

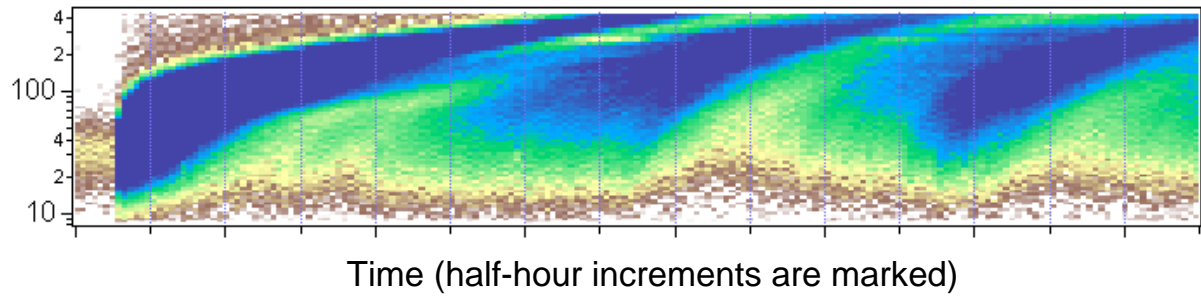


Figure 2

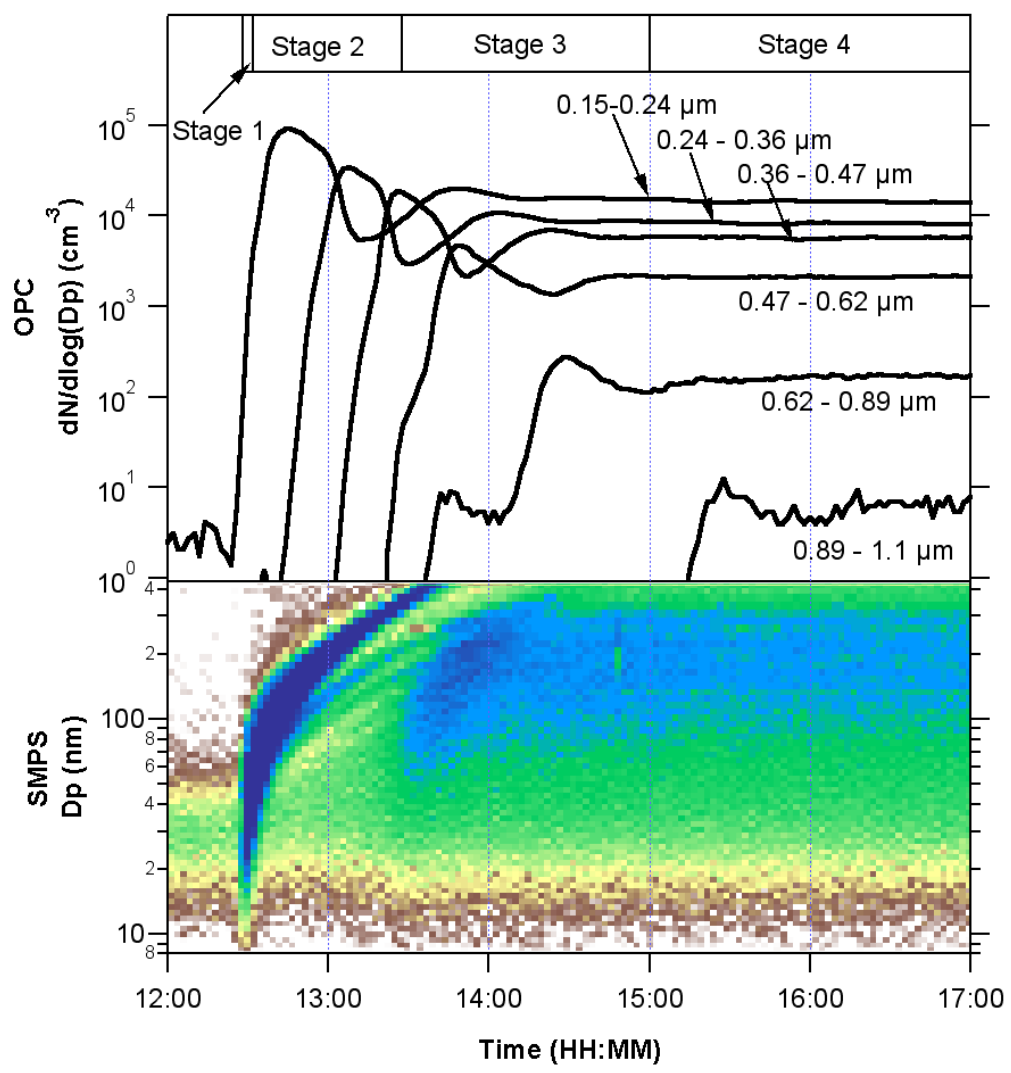

Figure 3

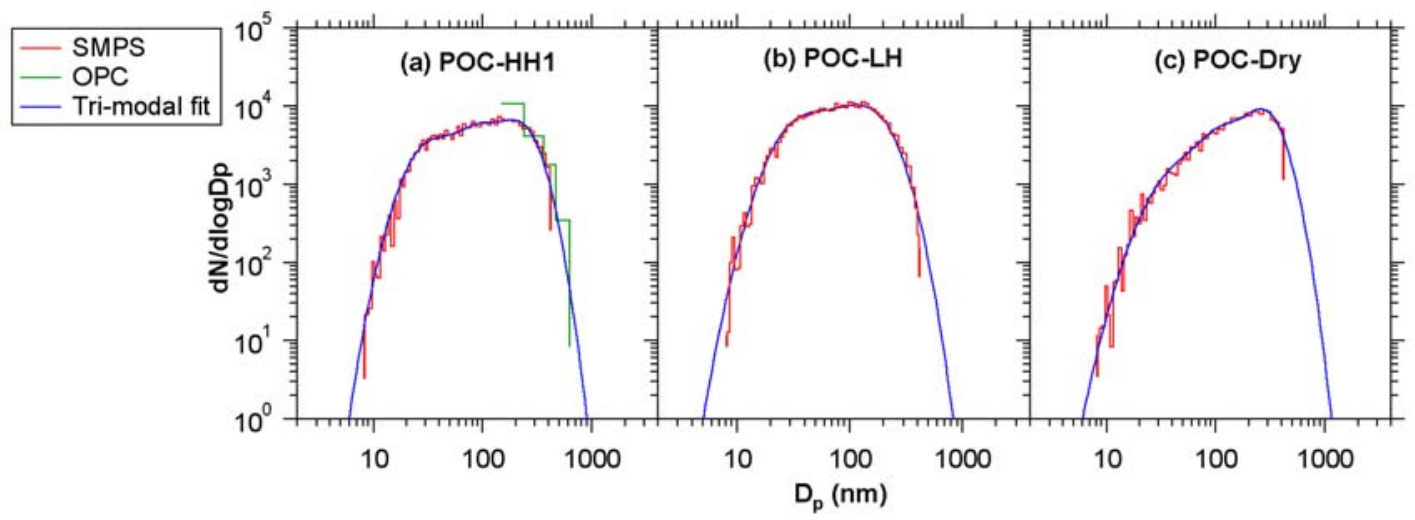




\section{Figure 4}
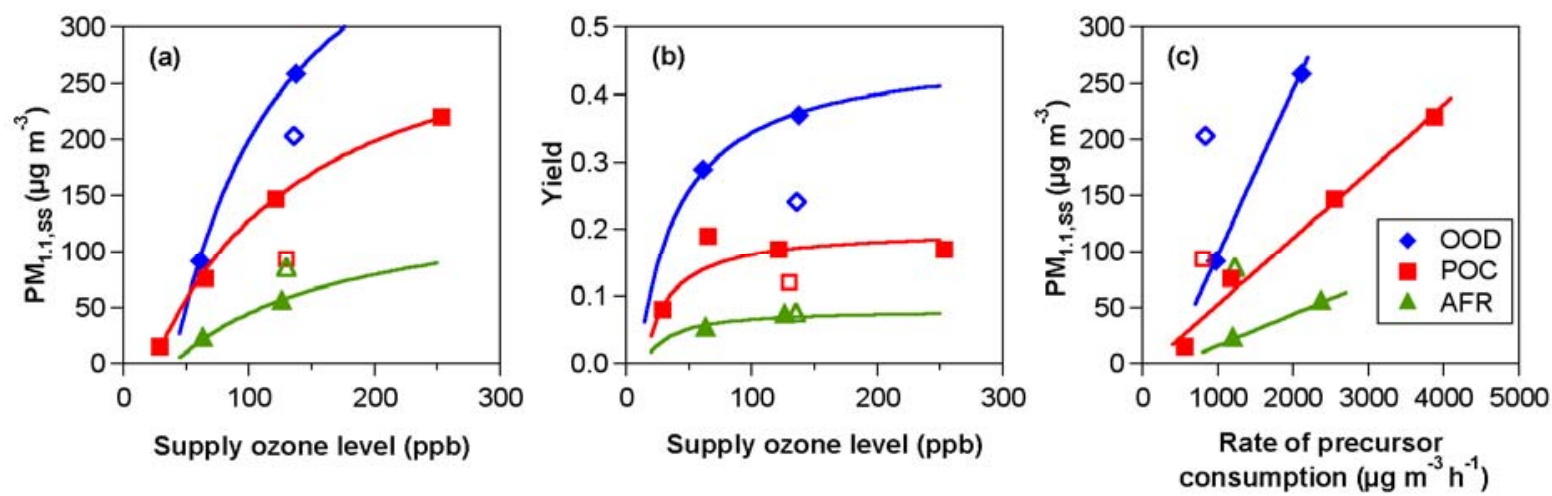

\section{Figure 5}

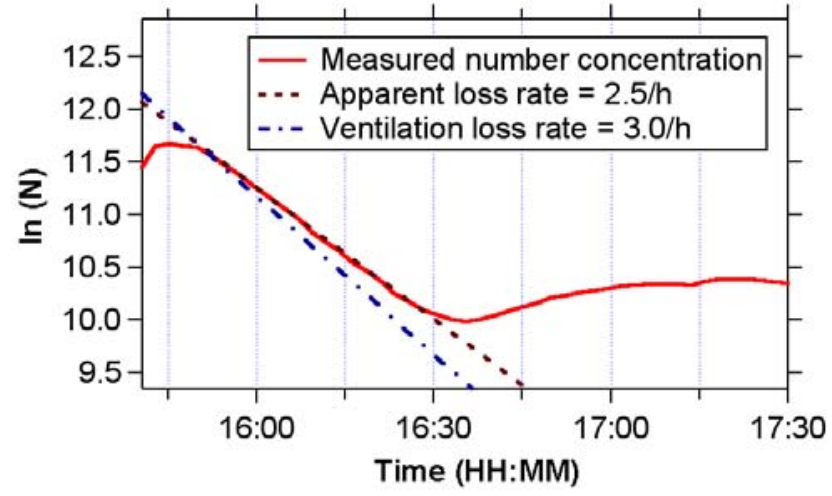

\section{Figure 6}

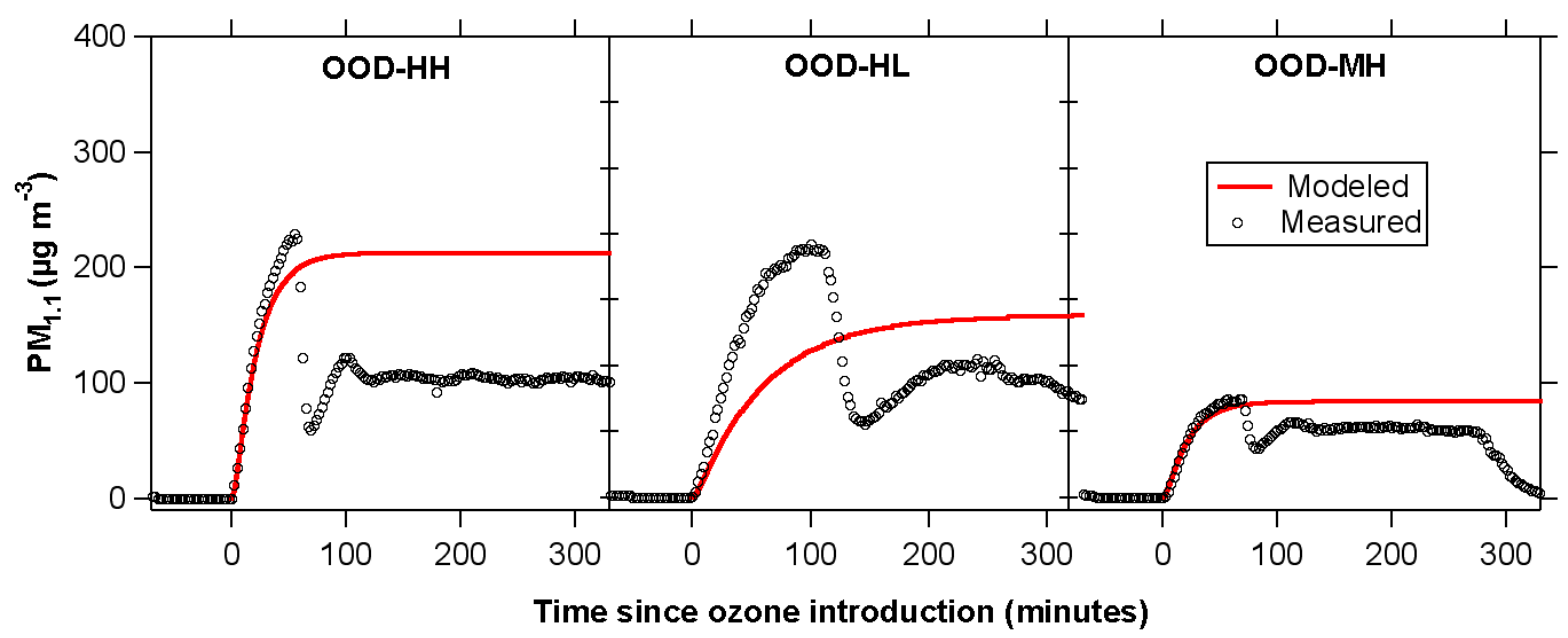

